\title{
Modelo bancario e inclusión financiera del territorio español durante la Gran Recesión: un análisis comparativo entre Banca Social, Cooperativa y Comercial
}

\author{
Beatriz Fernández-Olit ${ }^{1}$
}

Recibido: 28 de octubre de 2019 / Aceptado: 5 de marzo de 2020 / Publicado: 28 de julio de 2020

Resumen. Este artículo se centra en la importancia de las sucursales bancarias para la inclusión financiera del territorio, con independencia de que la digitalización favorezca en parte la prestación de servicios. Partiendo de esta premisa, este trabajo revisa los factores que a nivel provincial determinan la reducción de sucursales bancarias en España durante el periodo de mayor intensidad de la Gran Recesión (2008-2013). Mediante un análisis clúster se analizan especialmente las diferencias entre tipologías de entidades bancarias - así como entre entidades particulares-, respecto del proceso de reducción de la red territorial. Los resultados indican que la intensa contracción de la red de sucursales de las cajas de ahorro fue compensada por una absorción de parte de esa red por la banca comercial, que se mantuvo principalmente en zonas dinámicas y de carácter urbano, donde también aumentó el riesgo de discriminación bancaria por la desigualdad socioeconómica. Mientras, la banca cooperativa sostuvo las zonas rurales y envejecidas, llegando a ampliar su propia red y aprovechando los espacios vacíos dejados por las cajas. Las conclusiones reflexionan sobre los motivos que han justificado la reducción de la red de sucursales y proponen la consideración del nuevo marco normativo europeo, que garantiza el acceso de los ciudadanos a una cuenta bancaria y promueve nuevas estrategias de inclusión financiera. Finalmente, se presta atención a los principios que dieron origen y desarrollaron la banca social, a su actualización y aplicabilidad en el entorno post-crisis.

Palabras clave: Servicios Financieros; Territorio; Inclusión Financiera; Crisis; Banca Social; Banca Cooperativa; Análisis Clúster.

Claves Econlit: G01; G21; R1; P13.

\section{[en] Banking model and territorial financial inclusion during the Great Recession: a comparative analysis between Social, Cooperative and Commercial Banking}

Abstract. This article focuses on the importance of bank branches in the financial inclusion of the territory, regardless of whether the digitalization partly favours the provision of services. Assuming this premise, this paper reviews the factors determining the reduction of bank branches at a provincial level during the most severe period of the Great Recession (2008-2013). Using cluster analysis, the trends of reduction of the branches network are analysed considering the different categories of banking entities. The results indicate that the intense contraction of the saving banks' branch network was compensated by a partial absorption of branches by commercial banks, which remained in dynamic and urban areas, where also raised the risk of bank discrimination due to socioeconomic inequality. Meanwhile, cooperative banking sustained rural and aging areas, expanding its own network and taking advantage of the empty spaces left by the savings banks. The conclusions reflect on the reasons that have justified the reduction of the branch network, considering the new European regulatory framework, which guarantees citizens access to a bank account and promotes new financial inclusion strategies. Finally, the paper highlight the principles that gave rise to social banking, analysing their applicability in the post-crisis environment.

Keywords: Financial Services; Territory; Financial Inclusion; Crisis; Social Banking; Cooperative Banking; Cluster Analysis.

Sumario. 1. Introducción: La inclusión financiera territorial. Importancia en un mundo digitalizado 2. La crisis financiera y bancaria en España. Implicaciones en el marco de la desaparición de entidades y sucursales 3. Análisis empírico 4. Conclusiones. 5. Referencias bibliográficas.

Cómo citar. Fernández-Olit, B. (2020) Modelo bancario e inclusión financiera del territorio español durante la Gran Recesión: un análisis comparativo entre Banca Social, Cooperativa y Comercial. REVESCO. Revista de Estudios Cooperativos, vol. 135 , e69187. https://dx.doi.org/10.5209/reve.69187.

\footnotetext{
1 Universidad de Alcalá, España.

Dirección de correo electrónico: beatriz.olit@uah.es.
} 


\section{Introducción: La inclusión financiera territorial ${ }^{2}$. Importancia en un mundo digitalizado}

La tecnología está jugando un papel fundamental en la inclusión financiera de millones de personas en todo el mundo y especialmente en países en desarrollo, donde los microcréditos, la banca móvil y las tarjetas pre-pago ofrecen la oportunidad de utilizar servicios financieros a personas que se encontraban completamente excluidas de los mismos (Demirgüç-Kunt et al, 2018). La aplicación de las nuevas tecnologías al negocio bancario formal ha seguido una senda de crecimiento exponencial durante las últimas dos décadas. Poco se parece la banca actual en los países con aceptables niveles de bancarización a la de la década de los años 90, y una de las principales revoluciones ha sido la introducción de nuevos canales de comunicación entre los usuarios y las entidades. Esto ha llevado a cuestionar la existencia de las sucursales bancarias, particularmente durante la última década, en la que la penetración de la banca online ha sido más intensa. El escenario post-crisis ha cambiado la importancia de la sucursal en términos de inclusión financiera (Carbó y Rodríguez, 2015): la atención ya no se focaliza en el acceso físico a los servicios bancarios, sino en la extensión del uso bancario. Así, Demirgüç-Kunt et al (2018) analizan los parámetros de inclusión financiera mundial a través de Global Findex ${ }^{3}$ determinando el grado de uso de cuentas bancarias, y de otros productos como tarjetas de débito y crédito, el uso de banca online y los pagos digitales, o la utilización de dispositivos como los teléfonos móviles, pero no prestan atención a la utilización de sucursales bancarias.

No obstante, y aun reconociendo otros medios de acceso, el análisis académico ha mostrado una clara relación entre la proximidad de las sucursales bancarias y la accesibilidad a los servicios financieros, particularmente en economías desarrolladas (Leyshon et al, 2004; 2006). En décadas anteriores se ha mostrado que la red de sucursales ha constituido un importante mecanismo de protección frente a la exclusión financiera (Dymski y Veitch, 1996). De hecho, el análisis de la distribución territorial de las sucursales sigue vigente, como lo demuestra la generación de recientes estudios en países con alto nivel de digitalización como Estados Unidos (Kashian et al, 2015), Reino Unido (French et al, 2013; Degryse et al 2018), Europa continental (Richez-Battesti y Leseul, 2016; Papi et al, 2017; Gärtner y Fernández, 2018), o España (Alamá et al, 2015; Maudos, 2017) y se relaciona con la capacidad de inclusión financiera del territorio.

La definición de exclusión financiera territorial en el presente estudio retoma la definición ofrecida por la Comisión Europea (Anderloni et al, 2008:9):

"proceso por el cual la gente encuentra dificultades en el acceso y/o uso de servicios y productos financieros en el mercado general - mainstream-, que sean apropiados a sus necesidades y les permitan llevar una vida social normal en la sociedad a la que pertenecen".

La exclusión territorial se da cuando dichas dificultades derivan de una red insuficiente de sucursales en un territorio. La exclusión financiera es un concepto relativo y multifacético, al igual que lo es la pobreza, y su importancia puede evaluarse en tres dimensiones (Anderloni y Carluccio, 2007): una dimensión social, como integración de los individuos -y territorios- en una sociedad cada vez más 'financiarizada'; una dimensión económica, que permite el desarrollo total de las capacidades del individuo -y del territorio- y su contribución a la creación de valor, evitando ineficiencias del sistema; y una dimensión legal, cuestionando el acceso bancario como un servicio básico que debe garantizarse en condiciones adecuadas. La presencia física de las entidades bancarias tiene mucho que ver con la banca relacional y es importante para resolver problemas de exclusión financiera basados en factores de oferta (a través de la provisión de servicios adaptados a las necesidades de la población local). Pero también es necesaria para resolver problemas derivados de factores de demanda (autoexclusión, desconocimiento de los productos y servicios ofertados, etc.), facilitando que los potenciales usuarios puedan entender mejor el lenguaje financiero o el funcionamiento de productos y servicios, a través de la labor de intermediación del personal (Fernández-Olit, 2012). Finalmente, es una herramienta para evitar la doble discriminación (financiera y digital) que pueden sufrir los colectivos en situación de desigualdad socioeconómica y/o digital (Helsper, y Reisdorf, 2017).

Bowman el al (2014) identifican los procesos de reducción de la red bancaria con el declive económico y social de determinados territorios, principalmente los rurales y los urbanos de menor renta. Los espacios infra-atendidos en la prestación espacial de servicios bancarios formales pueden dar lugar a la entrada y desarrollo de otros agentes, incluyendo prestamistas informales, usureros, etc., definiendo lo que se ha denominado 'ecosistemas financieros' característicos de cada territorio (Coppock, 2013). La falta de equilibrio entre las tipologías de oferentes de servicios financieros en los territorios repercute negativamente

\footnotetext{
En el presente artículo se utilizará indistintamente los términos exclusión financiera e inclusión financiera, considerándolos antónimos, sin perjuicio de las definiciones concretas que se realicen durante el texto.

3 Global Findex Database es una base de datos auspiciada por el Banco Mundial en la que se recoge información sobre ahorro, crédito, pagos y gestión de riesgo financiero en 140 países a través de entrevistas a más de 150.000 personas.
} 
en términos de inclusión financiera de la pyme y de los hogares (Appelyard, 2013), impidiendo o encareciendo el acceso a estos servicios. El presente trabajo se justifica como análisis de las tendencias que durante la Gran Recesión han determinado nuevas ecologías financieras territoriales: los cambios tanto de intensidad en la presencia bancaria, como en la tipología de agentes presentes (bancos comerciales y banca social - cajas de ahorro y cooperativas de crédito).

El objetivo principal de este artículo es revisar las dinámicas de reducción y concentración de sucursales durante la época de crisis económica y en un periodo de alta intensidad de la reestructuración bancaria española (2008 - 2013), caracterizado por ser el de mayor restricción de operaciones de crédito destinadas a familias y pymes (Zurita, 2014; Menéndez et al, 2017). Como objetivos secundarios, se (1) analizan las implicaciones de este proceso en cuanto al aumento de exclusión financiera y las barreras a nivel territorial, y (2) se revisan las diferencias de reorganización y comportamiento entre las entidades sociales de crédito (cooperativas y cajas) y de la banca convencional según las características socioeconómicas del territorio.

El apartado 2 realiza un análisis teórico y exploratorio de las tendencias de reducción de la red de sucursales bancarias en España, planteando la hipótesis de investigación. El apartado 3 desarrolla un análisis de conglomerados - o análisis clúster- de los territorios, en base a la reducción de sucursales y el comportamiento de las diferentes tipologías bancarias. Se aplica una prueba $\mathrm{T}$ de contraste de medias para muestras independientes, que permite identificar diferencias socioeconómicas entre los territorios de expansión de la banca cooperativa y la banca comercial. Además, analiza el comportamiento individual de las entidades, determinando diferentes estrategias de resiliencia durante la crisis. Finalmente, el apartado 4 recoge las conclusiones.

\section{La crisis financiera y bancaria en España. Implicaciones en el marco de la desaparición de entidades y sucursales}

\subsection{Situación de la exclusión financiera territorial en España previa a 2008}

La sucursal ha seguido siendo un imperativo para el desarrollo del negocio bancario, pese a los avances tecnológicos, como lo demuestra la intensa expansión geográfica de las entidades bancarias españolas durante los primeros años del siglo XXI (Delgado et al, 2008). Durante ese periodo se constató una relación directa entre la presencia territorial y la concesión de crédito (Delgado et al, 2007), siendo ésta nula en aquellos territorios donde las entidades bancarias no disponían de sucursales.

No obstante, ya en el escenario pre-crisis de inicios de siglo se daban varios factores influyentes en términos de exclusión financiera, en su mayoría con origen en los procesos de apertura de las décadas anteriores (Carbó et al, 2005):

La competencia aumentó particularmente en el periodo anterior al año 2008, consecuencia de la liberalización regulatoria de los 90, con la eliminación de las restricciones territoriales, y de los bajos tipos de interés de inicios del siglo XXI. Esto fomentó una mayor homogeneidad entre la banca social y la banca comercial, cobró protagonismo el modelo de banca transaccional, basado en el uso de datos, y se redujo la especialización de las entidades. Alamá y Tortosa-Ausina (2012) corroboran la tendencia de las cajas de ahorro a competir vía sucursal - rival precedence - en los territorios donde los bancos ya se habían establecido.

Justamente este aumento de competencia cuestionaba la supervivencia de estructuras de costes insostenibles en un entorno no protegido, por lo que se planteaba el riesgo de desertificación bancaria de las poblaciones más pequeñas y pobres. Bernad et al (2008) señalan el doble filo de los procesos de desregulación bancaria en relación a la inclusión financiera: por un lado aumentan el nivel de competencia del mercado bancario, favoreciendo la eficiencia y la disminución de costes, y la expansión de la red de sucursales, factores que benefician a los consumidores; por otro lado, fenómenos como las fusiones o la desaparición de entidades reducen la competencia y favorecen el abandono de determinadas zonas o colectivos (Bowman et al, 2014). Lo cierto es que, siendo un aspecto ya de relevancia para los primeros análisis de la exclusión financiera territorial en España (Carbó y López del Paso, 2002), la vinculación de las cajas de ahorro ${ }^{4}$ y cooperativas de crédito con sus zonas de origen permitió mantener una amplia cobertura de las poblaciones más vulnerables, al menos hasta el inicio de la crisis de 2008 (Fernández-Olit, 2012).

Sin embargo, el modelo de 'maximización de valor para los accionistas', propio de la banca comercial, ha ido cobrando peso a medida que la banca social ha ido reduciendo el suyo en el sistema financiero. La maximización del retorno para el grupo de interés 'accionistas' implica ajustar los precios en relación al riesgo de la clientela, eliminar el subsidio cruzado de costes, y priorizar a los clientes más ricos en el acceso 
y atención bancaria, incluso a nivel de servicios como los ofertados a través de los call centers (Carbó et al, 2005).

Los principales estudios realizados en España en el periodo pre-crisis sobre la exclusión financiera territorial se recogen en la tabla 1 . Todos encuentran relación entre factores sociodemográficos y de tipología bancaria, y la localización de sucursales. Se centran fundamentalmente en valorar la disponibilidad de sucursales bancarias en un territorio.

Tabla. 1. Principales estudios sobre exclusión financiera territorial en España.

\begin{tabular}{|c|c|c|c|}
\hline ESTUDIO & VARIABLE & DETERMINANTES & MÉTODO \\
\hline $\begin{array}{l}\text { Martin- } \\
\text { Oliver } \\
(2019)\end{array}$ & $\begin{array}{l}\text { Distancia física } \\
\text { entre sucursales } \\
\text { Años } 2008 \text { y } 2014 .\end{array}$ & $\begin{array}{l}\text { Población total; Renta; Tasa } \\
\text { analfabetismo; Población } \\
\text { >64 años; Desempleo }\end{array}$ & $\begin{array}{l}\text { Modelo Probit Ordenado } \\
\text { Polígonos de Thiessen } \\
\text { Archivo Histórico de la } \\
\text { Guía de la Banca Ediban. }\end{array}$ \\
\hline $\begin{array}{c}\text { Alamá et al } \\
\text { (2015) }\end{array}$ & $\begin{array}{l}\text { Número de } \\
\text { sucursales por } \\
\text { municipio (esperado } \\
\text { y basal) } \\
\text { Años } 2004 \text { y } 2008 .\end{array}$ & $\begin{array}{l}\text { Desempleo (proxy de } \\
\text { actividad económica); } \\
\text { Densidad de población; } \\
\text { Población extranjera; } \\
\text { Provincia y municipio de } \\
\text { origen de la entidad } \\
\text { bancaria; } \\
\text { Número de sucursales de } \\
\text { otra tipología bancaria }\end{array}$ & $\begin{array}{l}\text { Modelo de regresión de } \\
\text { Poisson en el marco de } \\
\text { Modelo Linear Mixto } \\
\text { Generalizado (GLMM). } \\
\text { Archivo Histórico de la } \\
\text { Guía de la Banca Ediban. }\end{array}$ \\
\hline $\begin{array}{l}\text { Alamá y } \\
\text { Tortosa- } \\
\text { Ausina } \\
(2012)\end{array}$ & 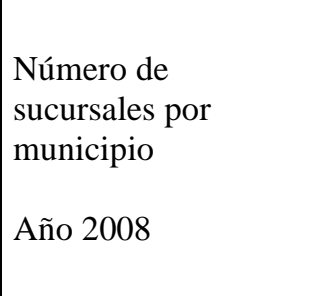 & $\begin{array}{l}\text { Vehículos (proxi de renta); } \\
\text { Desempleo; } \\
\text { Actividad comercial general } \\
\text { y minorista; } \\
\text { Actividad de construcción; } \\
\text { Turismo; } \\
\text { Densidad de población }\end{array}$ & $\begin{array}{l}\text { Regresión cuantílica basada } \\
\text { en el Anuario Económico } \\
\text { de La Caixa }\end{array}$ \\
\hline $\begin{array}{l}\text { Bernad et al } \\
\quad(2008)\end{array}$ & $\begin{array}{l}\text { Número de } \\
\text { sucursales en } \\
\text { municipios medios, } \\
\text { de baja y alta renta. } \\
\text { Años 1996, 2000 y } \\
2004\end{array}$ & $\begin{array}{l}\text { Población total; } \\
\text { Densidad de población; } \\
\text { Renta }\end{array}$ & $\begin{array}{l}\text { Mínimos Cuadrados } \\
\text { Ordinarios (OLS) basados } \\
\text { en el Anuario Económico } \\
\text { de La Caixa. }\end{array}$ \\
\hline $\begin{array}{l}\text { Carbó y } \\
\text { López del } \\
\text { Paso (2002) }\end{array}$ & $\begin{array}{l}\text { Municipios de más } \\
\text { de } 1000 \text { habitantes } \\
\text { excluidos (sin } \\
\text { sucursal), o } \\
\text { rescatados por las } \\
\text { cajas de ahorro. }\end{array}$ & $\begin{array}{l}\text { Renta; } \\
\text { Desempleo; } \\
\text { Actividad comercial } \\
\text { minorista; } \\
\text { Actividad de construcción; } \\
\text { Penetración de telefonía e } \\
\text { internet }\end{array}$ & $\begin{array}{l}\text { Análisis descriptivo basado } \\
\text { en el Anuario Económico } \\
\text { de La Caixa }\end{array}$ \\
\hline
\end{tabular}

Fuente: elaboración propia.

La investigación en el caso español muestra el importante papel que cajas de ahorro y cooperativas de crédito han jugado en las últimas décadas en términos de inclusión financiera de los colectivos y zonas más vulnerables (Carbó y López del Paso 2002; Bernad et al, 2008; Alamá y Tortosa, 2012). Esto concuerda con las conclusiones de numerosos estudios de enfoque territorial en el entorno europeo (Leyshon et al, 2004; French et al, 2013) y también en la percepción de mayor cercanía en las relaciones con los clientes de la banca social (Waite y Devlin, 2012; Martin-Oliver, 2019). Se atribuye a estas tipologías bancarias ciertas ventajas para especializarse en la banca relacional, como la eficiencia competitiva y los menores costes de agencia derivados de estructuras menos jerarquizadas (Delgado et al, 2007). Sin embargo, los traumáticos procesos de transformación de las cajas de ahorro desde una estructura bancaria sin ánimo de lucro a sociedades anónimas y la asunción de estrategias de segmentación de mercado basadas en la rentabilidad del cliente, incluso en el caso de las cooperativas de crédito (Palomo-Zurdo y Sanchís-Palacio, 2008), plantean dudas respecto al futuro de su rol inclusivo.

El año 2008 supuso un momento de ruptura con una época de exuberancia económica y exceso de confianza en un entorno de información imperfecta, características comunes al inicio de las crisis bancarias 
en España (Sudrià i Triay, 2014). La crisis reveló debilidades en el balance y en el gobierno de muchas entidades españolas, particularmente de las cajas de ahorro que habían participado con especial ahínco en la carrera expansiva de los primeros años del siglo XXI, asumiendo mayores riesgos (Goddard et al, 2009).

A partir de 2008 se asistió a un reforzamiento regulatorio con el objetivo de recuperar la confianza, estabilidad y eficiencia del sistema financiero español. En un periodo de cinco años, el sector bancario español mutó desde un sistema equilibrado, con diferentes modelos de propiedad y mercados bancarios regionales, a uno mucho más centralizado y consolidado, dominado por sociedades anónimas (Cruz-García et al, 2018; EBF 2013: 81). En 2012 los cuatro mayores bancos españoles poseían más del 57\% de los activos del sector, con expectativas de aumentar esta concentración hasta niveles nada convenientes para la estabilidad financiera (García-Montalvo, 2014). Esta estrategia de concentración, fundamentada en necesidades urgentes de reforzamiento del capital, podría resultar contraproducente, pues una mayor diversidad en el mercado bancario está asociada a mayor eficiencia (Delgado et al, 2008) ${ }^{5}$, a mayores niveles de acceso financiero (Banco Mundial, 2014), y a menores riesgos derivados de asimetrías de información y poder en la relación entre entidades financieras y clientes (Quintás, 2006). Así, la pérdida de diversidad podría hacer más vulnerables a los consumidores, afectando a la competencia y aumentando los precios ${ }^{6}$.

Maudos (2017) identifica estos dos factores (concentración del mercado y la reestructuración de las cajas de ahorro) como los catalizadores del cierre de 14.741 sucursales, el 27\% de la red total, entre 2008 y 2015. Esta reducción de sucursales ha ido acompañada por una disminución paralela del personal del sector bancario.

Ante este panorama cobran relevancia otros aspectos relacionados con la inclusión financiera y que van más allá de las dificultades de acceso a sucursales: la reestructuración bancaria puede haber afectado a aspectos como la calidad del servicio y las dificultades de uso para determinados colectivos, incluidos aquellos no habituados al uso de las nuevas tecnologías y que requieren mayor atención del personal bancario (Fernández-Olit et al, 2018).

\subsection{Reducción de la red de sucursales según regiones y tipología de entidades bancarias}

Un análisis descriptivo (Figura 1) permite constatar la existencia de pautas regionales en la 'intensidad de variación' de sucursales bancarias en el período 2008-2013. Ésta se define como la proporción de sucursales que variaron respecto al número existente en 2008. En la mayor parte de las provincias españolas fue negativa.

Cataluña, Galicia, La Rioja o Castilla y León fueron comunidades muy afectadas por la pérdida de oficinas bancarias, con porcentajes que superaron el 20\%. También se observa este efecto en las provincias del litoral mediterráneo, incluidas las Islas Baleares, en Navarra, en Madrid, y en parte de Canarias. Así, observamos que la desaparición de sucursales bancarias durante la crisis reequilibró el sobredimensionamiento de la red en provincias que habían experimentado un alto desarrollo urbanístico y poblacional durante la década anterior, lo cual puede reflejar una reacción de ajuste al mercado. Por el contrario, la menor intensidad de reducción la vemos en territorios aislados (Melilla) o con fuerte carácter rural (Cuenca o Teruel).

Debe tenerse en cuenta que la eficiencia de las entidades bancarias de la economía social (cajas y cooperativas crédito) se habían mantenido en niveles cercanos al resto de la banca y que incluso las pruebas de resistencia bottom-up para evaluar las necesidades de capital del sistema bancario español en el marco del Programa de Asistencia Financiera por parte de la Comisión Europea, el BCE y el FMI, corroboraron su mayoritaria solvencia y viabilidad (EBF, 2013).

6 Una evidencia palpable de este fenómeno es la denominada 'guerra de comisiones de los cajeros' desencadenada a mediados de 2015 por la decisión de las grandes entidades bancarias de subir las comisiones de uso a los no clientes. Véase, por ejemplo, El País, Economía, 26/09/2015: "Los grandes bancos preveían triplicar las tasas con la 'guerra de los cajeros'. 
Figura. 1. Variación de sucursales según provincias (2008-2013).

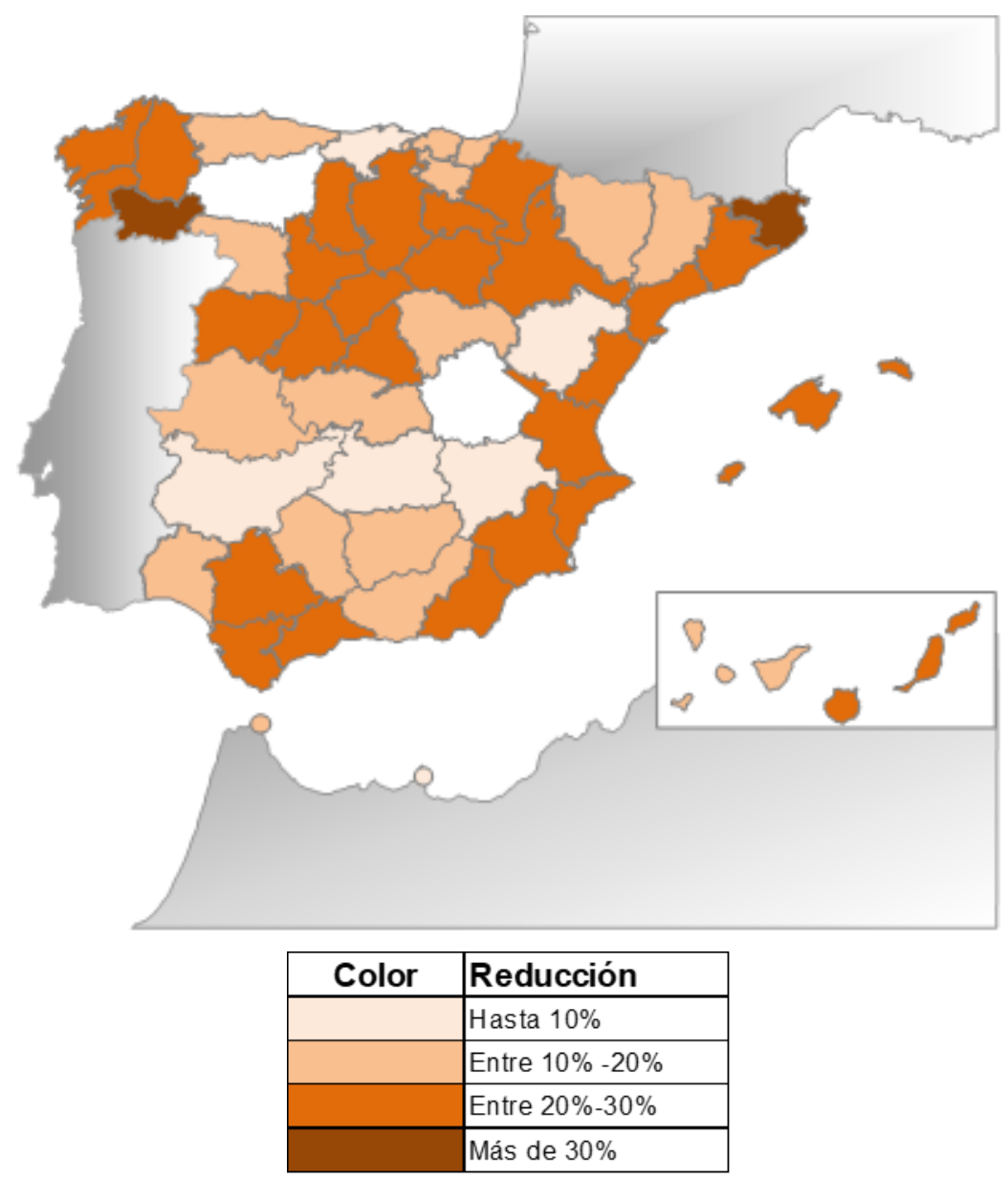

Fuente: elaboración propia con datos del Anuario Histórico de la Guía de la Banca Ediban.

Teniendo en cuenta la teoría de la prioridad de mercado (Evanoff, 1988), podemos inferir que las cajas de ahorro y las cooperativas de crédito españolas han mantenido un esfuerzo particular en la atención de las zonas rurales y las provincias de menor población (Fernández-Olit, 2012). Esto nos lleva a considerar la posibilidad de que la banca española hubiera respondido al problema de exclusión financiera de las zonas rurales, pero no a la potencial generación de dificultades en el uso bancario en regiones urbanas, intensificadas durante los años de crisis y el aumento de la desigualdad social.

La hipótesis que se plantea a partir del análisis teórico y exploratorio es:

H1: Los bancos, cajas de ahorro y cooperativas de crédito siguieron durante la crisis diferentes patrones de variación de sucursales según las características socioeconómicas del territorio.

\section{Análisis empírico}

\subsection{Base de datos y variables}

En el análisis empírico se ha utilizado el Archivo Histórico de la 'Guía de la Banca' de la editorial Maestre-Ediban, con información de corte transversal para los años 2008 y 2013. Esta base de datos proporciona la ubicación concreta de las sucursales bancarias para el conjunto de entidades de depósito operativas en el mercado español, de las cuales se han seleccionado aquellas dirigidas al mercado minorista y que disponen de red de sucursales ${ }^{7}$. Las entidades bancarias se han clasificado en bancos, cajas de ahorro y cooperativas de crédito atendiendo al carácter histórico de cada entidad y al código mantenido en la base de

Se han incluido las filiales de bancos extranjeros que operan bajo ficha del Banco de España y que en algún momento han absorbido la red de otras entidades bancarias españolas. 
datos. La información regional de carácter demográfico y socio-económico se ha obtenido del Instituto Nacional de Estadística y del Ministerio de Fomento.

En los análisis realizados en el entorno español sobre inclusión financiera y red bancaria, la variable más utilizada ha sido el número total de sucursales por municipio (véase tabla 1). Es una variable adecuada para un análisis en un entorno estable, pero para captar el efecto que la reducción de la red bancaria durante un periodo puede haber tenido sobre la calidad de servicio y las dificultades de uso, se ha preferido utilizar la 'intensidad de variación de sucursales'. Esta variable fue utilizada por French et al (2013) para estudiar el proceso de contracción de la red de sucursales entre 2003 y 2012 en Reino Unido. Así, se ha definido para cada provincia y para las tres diferentes tipologías bancarias: bancos, cajas y cooperativas de crédito, con el objetivo de recoger diferencias de comportamiento por grupo en el proceso de contracción de la red bancaria durante la crisis.

Para la caracterización socioeconómica del territorio se han escogido las siguientes variables, (tabla 2): La variable 'densidad de población' es un determinante clásico en los modelos de establecimiento de sucursales bancarias, con un efecto moderador sobre el volumen de población (Bernad et al, 2008). También se incluye la 'población mayor de 65 años', asociada a un menor riesgo de exclusión financiera en los países más desarrollados (Anderloni et al, 2008), pero con mayor necesidad de atención en sucursal (Martin-Oliver, 2019). Se ha definido el 'índice de inmigración principal' que refleja la presencia de inmigrantes por motivos económicos procedentes de diferentes regiones globales (Rumanía, Ecuador, Marruecos y China) ${ }^{8}$, como ratio sobre la población total. Las minorías étnicas y la población inmigrante son grupos de riesgo de exclusión financiera (Aalbers, 2007; Anderloni y Carluccio, 2007). Dentro de las variables económicas se han seleccionado el 'nivel de desempleo' por cada mil habitantes y el 'PIB per cápita', que pueden entenderse como componentes del perfil rentabilidad-riesgo de la población de un territorio para las entidades bancarias. Se introduce también el número de 'unidades locales de negocio' por cada mil habitantes, como indicador del dinamismo económico; y la 'variación del precio de la vivienda', asumiendo que caídas mayores en los precios indican un menor dinamismo de la demanda de vivienda, factor determinante para la expansión de las sucursales bancarias en el periodo pre-crisis (Delgado et al, 2008). Finalmente se introduce en el modelo la ratio de 'acceso a internet' sobre el total de hogares del territorio, factor relevante para la expansión de canales de servicio bancario alternativos como la banca online. La escala de todas las variables, dependientes e independientes, ha sido ajustada con el fin de homogeneizar las unidades de medida. Comportamiento diferencial entre bancos comerciales, cajas de ahorro y cooperativas de crédito.

Tabla. 2. Variables y fuentes de información

\begin{tabular}{|c|c|}
\hline Tipo de variable & Fuente \\
\hline \multicolumn{2}{|l|}{ Comportamiento según tipología bancaria } \\
\hline $\begin{array}{l}\text { Intensidad de variación sucursales (2008-2013) (ratio) por } \\
\text { tipología bancaria (VRBANCOS, VRCAJAS, VRCC) }\end{array}$ & $\begin{array}{l}\text { Archivo Histórico de la Guía de la Banca de } \\
\text { Ediban }\end{array}$ \\
\hline \multicolumn{2}{|l|}{ Caracterización socioeconómica del territorio } \\
\hline $\begin{array}{l}\text { Variables demográficas } \\
\text { Densidad de población } \\
\text { (miles hab. } / \mathrm{km}^{2} \text { ) } \\
\text { Porcentaje de población de más de } 65 \text { años (ratio) } \\
\text { Índice de inmigración principal }\end{array}$ & $\begin{array}{l}\text { Instituto Nacional de Estadística (INE). } \\
\text { Cifras de población y territorio. }\end{array}$ \\
\hline $\begin{array}{l}\text { Variables económicas y laborales } \\
\text { Desempleados por } 100 \text { habitantes } \\
\text { PIB per cápita (miles } € \text { ) }\end{array}$ & $\begin{array}{l}\text { INE. Encuesta de Población Activa 3T2013 } \\
\text { y Contabilidad Regional de España - Base } \\
2010\end{array}$ \\
\hline \multicolumn{2}{|l|}{ Dinamismo económico y tecnológico del territorio } \\
\hline Unidades locales por 1000 habitantes & $\begin{array}{l}\text { Explotación Estadística del Directorio } \\
\text { Central de Empresas } 2013 \\
\text { Ministerio de Fomento. Valor medio de las }\end{array}$ \\
\hline Variación del precio de la vivienda (2008-2013) (ratio) & $\begin{array}{l}\text { Transacciones Inmobiliarias de Vivienda } \\
\text { Libre. }\end{array}$ \\
\hline Hogares con acceso a internet (ratio) & $\begin{array}{l}\text { Censos de Población y Viviendas } 2011 . \\
\text { Resultados definitivos. }\end{array}$ \\
\hline
\end{tabular}

Fuente: elaboración propia a partir de las fuentes mencionadas. 


\subsection{Reducción de la red de sucursales según tipologías bancarias y características del territorio}

Para definir características comunes de los territorios donde uno u otro subsector han tenido diferente comportamiento, se ha optado por utilizar un análisis clúster, o análisis de conglomerados. El análisis clúster permite determinar conglomerados de objetos con un alto grado de homogeneidad interna (dentro del conglomerado) y de heterogeneidad externa (entre conglomerados) (Hair et al, 2006). Ha sido anteriormente aplicado al análisis de la exclusión financiera territorial por Horska et al (2013) y Joassart-Marcelli y Stephens (2010).

De manera exploratoria, previa al análisis, se han definido los gráficos de dispersión que relacionan la variación relativa de sucursales en los diferentes subsectores y por provincias (figura 2). Se puede distinguir una tendencia de agrupación doble: un gran núcleo de territorios, agrupado bajo la reducción intensa de sucursales por parte de cajas y bancos; y un segundo núcleo, más disperso, de provincias con reducción muy alta en el subsector cajas, cierta reducción en las cooperativas de crédito, y expansión del subsector bancos.

Figura 2. Gráficos de dispersión de variación de sucursales por subsector bancario y por provincia (2008-2013)
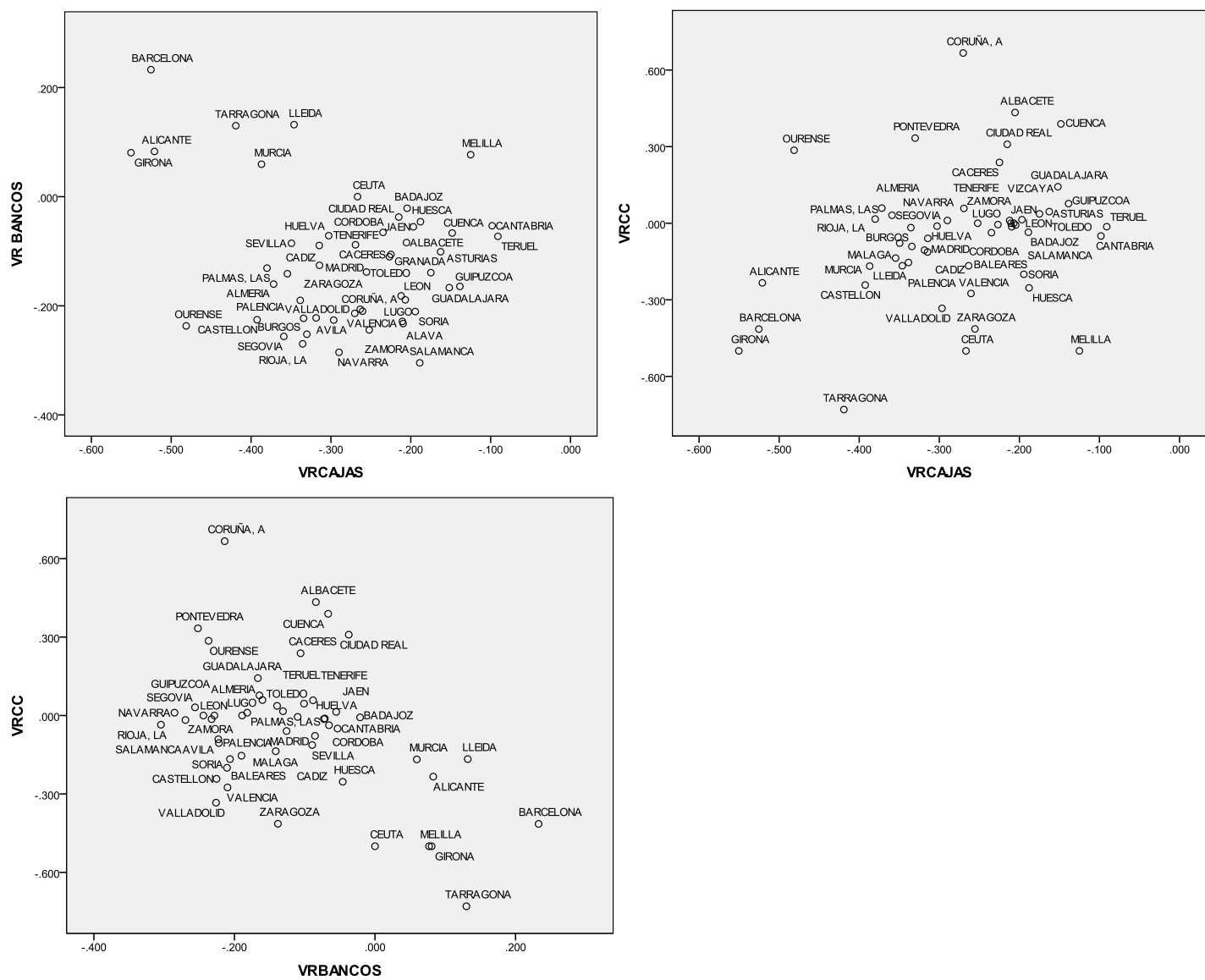

Fuente: elaboración propia a partir de la Guía de la Banca de Ediban

La aplicación de un análisis de conglomerados de K-medias ${ }^{9}$ ha dado como resultado la división de la muestra en dos conglomerados de tamaño comparable y centros diferenciados (véase Apéndice). El primer grupo engloba los territorios donde los bancos han expandido, mantenido o reducido moderadamente su red de sucursales y donde la red de cajas y cooperativas se ha contraído con más intensidad. En parte, este efecto contrario puede explicarse porque determinados bancos incorporaron la red comercial de cajas de ahorro en situación crítica, efecto intenso en algunos territorios como el Levante mediterráneo. El conglomerado 2 queda caracterizado por regiones donde el subsector de cooperativas de crédito mantuvo o incluso se expandió durante la crisis. En ellas se ha experimentado a su vez una intensa reducción de la red de las cajas, compartida a un nivel más moderado por los bancos comerciales.

9 El análisis de conglomerados o análisis cluster refiere a un grupo de técnicas de análisis multivariante que agrupa objetos basándose en uno o varios criterios de selección predeterminados, maximizando la homogeneidad intra-grupos y la heterogeneidad entre los agregados (Hair et al, 2006). 
Tabla. 3. Número de provincias en cada conglomerado

\begin{tabular}{|ll|r|}
\hline Conglomerado & 1 & 18.000 \\
& 2 & 34.000 \\
Válidos & & 52.000 \\
Perdidos & & .000 \\
\hline
\end{tabular}

Fuente: elaboración propia

Tabla. 4. ANOVA para tipologías bancarias

\begin{tabular}{|c|c|c|c|c|c|c|}
\hline & \multicolumn{2}{|c|}{ Conglomerado } & \multicolumn{2}{|c|}{ Error } & \multirow[b]{2}{*}{$\mathrm{F}$} & \multirow[b]{2}{*}{ Sig. } \\
\hline & $\begin{array}{c}\text { Media } \\
\text { cuadrática }\end{array}$ & $\mathrm{gl}$ & $\begin{array}{c}\text { Media } \\
\text { cuadrática }\end{array}$ & $\mathrm{Gl}$ & & \\
\hline VRBANCOS & .130 & 1 & .012 & 50 & 10.730 & .002 \\
\hline VRCAJAS & .084 & 1 & .010 & 50 & 8.471 & .005 \\
\hline VRCC & 1.727 & 1 & .030 & 50 & 58.105 & .000 \\
\hline
\end{tabular}

Fuente: elaboración propia

Tabla. 5. Centros de los conglomerados finales

\begin{tabular}{|l|r|r|}
\hline \multirow{2}{*}{} & \multicolumn{2}{|c|}{ Conglomerado } \\
\cline { 2 - 3 } & \multicolumn{1}{|r|}{2} \\
\hline VRBANCOS & -.049 & -.154 \\
VRCC & -.333 & -.249 \\
\multicolumn{2}{|r}{-.306} & .077 \\
\hline
\end{tabular}

Para comprobar si existen diferencias sociodemográficas entre los territorios categorizados en ambos conglomerados se ha efectuado una prueba T de contraste de medias para muestras independientes (tablas 6 y 7). Hay dos factores significativos en un nivel de confianza del 95\%: los porcentajes de población mayor de 65 años y de población inmigrante. Las provincias donde la red de bancos tiene un comportamiento más positivo, pese a notables reducciones de la red de cajas y cooperativas, son territorios con población más joven y más presencia de inmigrantes, lo que concuerda con los resultados obtenidos por Alamá et al (2015). Este conglomerado incluye, por ejemplo, a Cataluña y a casi todas las provincias mediterráneas. Si atendemos a las regiones en las que la red de cooperativas experimenta un ligero crecimiento y donde las cajas han mantenido un comportamiento comparativamente menos negativo -conglomerado 2- observamos que responden a un mayor envejecimiento de la población, característico de los territorios rurales del interior de la península, y una menor presencia de población inmigrante, aspecto diferencial de, por ejemplo, las provincias cantábricas y gallegas. Casos atípicos serían Almería, clasificado en este conglomerado por la fortaleza de su sector bancario cooperativo, o Madrid, lo que muestra una mayor variedad de territorios recogidos en este grupo. 
Tabla. 6. Estadísticos de grupo

\begin{tabular}{|ll|r|r|r|r|}
\hline & $\begin{array}{l}\text { Número inicial de } \\
\text { casos }\end{array}$ & $\mathrm{N}$ & \multicolumn{1}{c|}{ Media } & Desviación típ. & $\begin{array}{c}\text { Error típ. de la } \\
\text { media }\end{array}$ \\
\hline POB 65 & 1 & 18 & .173084 & .0385398 & .0090839 \\
& 2 & 34 & .199814 & .0425796 & .0073023 \\
\hline INMIGR & 1 & 18 & .062023 & .0344230 & .0081136 \\
& 2 & 34 & .036713 & .0289525 & .0049653 \\
\hline DESEMP & 1 & 18 & 12.050403 & 3.3343210 & .7859070 \\
& 2 & 34 & 12.445469 & 3.8263371 & .6562114 \\
\hline PIBPCAP & 1 & 18 & 21914.00 & 3744.066 & 882.485 \\
& 2 & 34 & 20697.74 & 4694.844 & 805.159 \\
\hline UNIDLOC & 1 & 18 & 7.326010 & 1.1615596 & .2737822 \\
& 2 & 34 & 7.177291 & .6841267 & .1173268 \\
\hline PRECVIV & 1 & 18 & -.31257 & .105257056400 & .024809326116 \\
& 2 & 34 & -.29213 & .100995165819 & .017320528044 \\
\hline INTERN & 1 & 18 & .541861 & .0559175 & .0131799 \\
& 2 & 34 & .492374 & .0732366 & .0125600 \\
\hline
\end{tabular}

Fuente: elaboración propia

Tabla. 7. Prueba de muestras independientes

\begin{tabular}{|c|c|c|c|c|c|c|c|c|c|c|}
\hline & \multicolumn{2}{|c|}{$\begin{array}{c}\text { Prueba de } \\
\text { Levene para } \\
\text { la igualdad } \\
\text { de varianzas }\end{array}$} & \multicolumn{7}{|c|}{ Prueba T para la igualdad de medias } \\
\hline & & \multirow[b]{2}{*}{ F } & \multirow[b]{2}{*}{ Sig. } & \multirow[b]{2}{*}{$\mathrm{t}$} & \multirow[b]{2}{*}{ gl } & \multirow{2}{*}{$\begin{array}{c}\text { Sig. } \\
\text { (bilatera } \\
1 \text { ) } \\
\end{array}$} & \multirow{2}{*}{$\begin{array}{l}\text { Diferencia } \\
\text { de medias }\end{array}$} & \multirow{2}{*}{$\begin{array}{l}\text { Error típ. } \\
\text { de la } \\
\text { diferencia }\end{array}$} & \multicolumn{2}{|c|}{$\begin{array}{l}95 \% \text { Intervalo de } \\
\text { confianza para la } \\
\text { diferencia }\end{array}$} \\
\hline & & & & & & & & & Inferior & Superior \\
\hline$\%$ POP 65 & $\begin{array}{l}\text { Se han asumido } \\
\text { varianzas iguales }\end{array}$ & .627 & .432 & -2.223 & 50 & $.031 * *$ & -.0267306 & .0120242 & -.0508818 & -.0025794 \\
\hline IMMIGR & $\begin{array}{l}\text { Se han asumido } \\
\text { varianzas iguales }\end{array}$ & .848 & .362 & 2.808 & 50 & $.007 * *$ & .0253104 & .0090133 & .0072067 & .0434142 \\
\hline DESEMP & $\begin{array}{l}\text { Se han asumido } \\
\text { varianzas iguales }\end{array}$ & 2.134 & .150 & -.370 & 50 & .713 & -.3950658 & 1.0687442 & -2.5417016 & 1.7515701 \\
\hline PIBCAP & $\begin{array}{l}\text { Se han asumido } \\
\text { varianzas iguales }\end{array}$ & .185 & .669 & .949 & 50 & .347 & 1216.265 & 1281.024 & -1356.747 & 3789.276 \\
\hline UNIDLOC & $\begin{array}{l}\text { Se han asumido } \\
\text { varianzas iguales }\end{array}$ & 2.239 & .141 & .582 & 50 & .563 & .1487190 & .2553896 & -.3642461 & .6616840 \\
\hline PRECVIV & $\begin{array}{l}\text { Se han asumido } \\
\text { varianzas iguales }\end{array}$ & .025 & .875 & -.684 & 50 & .497 & -.02043637 & .02986741 & -.0804268 & .0395541 \\
\hline INTERN & $\begin{array}{l}\text { Se han asumido } \\
\text { varianzas iguales }\end{array}$ & 1.466 & .232 & 2.502 & 50 & $.016 *$ & .0494876 & .0197765 & .0097652 & .0892099 \\
\hline
\end{tabular}

**Significativo bajo un nivel de confianza de $95 \%$; * Significativo bajo un nivel de confianza de $80 \%$

Fuente: elaboración propia

Conviene observar, con la precaución correspondiente al menor nivel de confianza, que la penetración de internet es inferior para el conglomerado 2 y refuerza su caracterización como territorios más envejecidos y menos diversos o tecnificados. Aun sin significación estadística aceptable, vemos que la renta per cápita tiende a ser menor en las provincias donde se da un comportamiento más favorable de cajas y cooperativas, en línea con los resultados de autores anteriores (Alamá y Tortosa, 2012, Bernard et al, 2008) que en el caso de la banca social y cooperativa planteaban la existencia un criterio más allá del económico para la implantación - o retención - territorial de las sucursales, en sintonía con la teoría de la prioridad de mercado.

\subsection{Un foco sobre el comportamiento particular de las entidades}

Delgado, Saurina y Townsend (2008) identificaron ocho patrones de expansión de las entidades bancarias vía sucursal en el periodo anterior a la crisis y establecieron tres conclusiones de especial relevancia para nuestro estudio: las estrategias de crecimiento fueron muy diversas y coexistieron en los mismos territorios; 
el crédito inmobiliario, a empresas y familias, constituyó un incentivo importante para la expansión de las redes; y una potencial reducción de la demanda de crédito plantearía la necesidad de un proceso de redimensionamiento.

Utilizando la 'intensidad de variación' en cuanto al número de sucursales de cada entidad -E'-, se ha dividido la muestra de entidades de depósito en nueve grupos que diferencian su comportamiento expansivo o contractivo durante el periodo 2008-2013. Adicionalmente se ha observado la distribución territorial de esta variación de sucursales para cada entidad (figura 3 ).

Tabla. 8. Tendencias de variación de la red de sucursales (2008-2013)

\begin{tabular}{|c|c|c|c|}
\hline GRUPO 1 & $\begin{array}{l}\text { Expansión muy } \\
\text { alta }(E>100 \%)\end{array}$ & $\begin{array}{l}3 \text { cooperativas de } \\
\text { crédito }\end{array}$ & $\begin{array}{c}\text { Entidades muy pequeñas o pequeñas que se expandieron sólo en su } \\
\text { provincia de origen (Madrid o Valencia) }\end{array}$ \\
\hline GRUPO 2 & $\begin{array}{c}\text { Expansión alta } \\
(100 \% \geq E \geq 50 \%)\end{array}$ & $\begin{array}{l}8 \text { cooperativas de } \\
\text { crédito }\end{array}$ & $\begin{array}{l}\text { Entidades muy pequeñas ( } 1 \text { o } 2 \text { sucursales iniciales) que se expandieron } \\
\text { exclusivamente en su provincia de origen (Castellón o Valencia) }\end{array}$ \\
\hline GRUPO 3 & $\begin{array}{l}\text { Expansión media } \\
(50 \%>\mathrm{E} \geq 10 \%)\end{array}$ & $\begin{array}{l}11 \text { cooperativas } \\
\text { de crédito } \\
3 \text { bancos } \\
\text { comerciales }\end{array}$ & $\begin{array}{c}\text { Grupo muy heterogéneo que engloba: } \\
\text { - cooperativas muy pequeñas, que crecieron a nivel local (C. Valenciana, } \\
\text { Cataluña, Sevilla, Asturias), } \\
\text { - cooperativas pequeñas y medianas con expansión autonómica } \\
\text { (Castilla-La Mancha, Extremadura y Canarias) } \\
\text { - bancos comerciales pequeños en expansión autonómica en Galicia y } \\
\text { Extremadura } \\
\text { - un banco muy grande en crecimiento moderado en todos los territorios }\end{array}$ \\
\hline GRUPO 4 & $\begin{array}{l}\text { Expansión ligera } \\
(10 \%>\mathrm{E}>0 \%)\end{array}$ & $\begin{array}{l}8 \text { cooperativas de } \\
\text { crédito } \\
1 \text { banco } \\
\text { comercial }\end{array}$ & $\begin{array}{c}\text { Grupo segmentado en: } \\
\text {-cooperativas muy pequeñas o pequeñas, con expansión a nivel } \\
\text { provincial o de regiones colindantes. } \\
\text { - banco comercial muy grande con expansión generalizada en muchas } \\
\text { provincias (en parte por lanzamiento de banca postal) }\end{array}$ \\
\hline GRUPO 5 & $\begin{array}{c}\text { Entidades } \\
\text { estables }(E=0 \%)\end{array}$ & $\begin{array}{l}18 \text { cooperativas } \\
\text { de crédito } \\
1 \text { caja de ahorros }\end{array}$ & $\begin{array}{l}\text { En su mayoría son entidades que ni cerraron ni abrieron sucursales. } \\
\text { Todas entidades muy pequeñas o pequeñas con expansión de ámbito } \\
\text { provincial o, en todo caso, en provincia colindante (Castilla-La Mancha, } \\
\text { C. Valenciana, Teruel, y Córdoba) }\end{array}$ \\
\hline GRUPO 6 & $\begin{array}{l}\text { Reducción ligera } \\
(0 \%>\mathrm{E} \geq-10 \%)\end{array}$ & $\begin{array}{l}10 \text { cooperativas } \\
\text { de crédito } \\
3 \text { cajas de ahorro }\end{array}$ & $\begin{array}{c}\text { Grupo segmentado en: } \\
\text { - entidades pequeñas o muy pequeñas, de carácter comarcal o regional, } \\
\text { que se reajustaron a nivel autonómico o en provincias colindantes, } \\
\text { mediante una combinación de crecimiento en territorios externos y } \\
\text { decrecimiento en la provincia de origen. } \\
\text { - entidades mayores, principalmente cajas de ahorro, se reconcentraron } \\
\text { en sus territorios (Euskadi, Aragón) y redujeron más intensamente la red } \\
\text { de provincias lejanas. }\end{array}$ \\
\hline GRUPO 7 & $\begin{array}{l}\text { Reducción media } \\
(-10 \%>E>-25 \%)\end{array}$ & $\begin{array}{l}3 \text { cooperativas de } \\
\text { crédito } \\
7 \text { cajas de ahorro } \\
5 \text { bancos } \\
\text { comerciales }\end{array}$ & $\begin{array}{c}\text { Tres sub-tendencias: } \\
\text {-bancos pequeños y regionales que decrecieron en su territorio de } \\
\text { origen. } \\
\text {-gran banca nacional (comercial y cajas de ahorro) que disminuyó la red } \\
\text { en todos los territorios, particularmente en Cataluña y grandes áreas } \\
\text { metropolitanas. } \\
\text {-Cajas y cooperativas provinciales y autonómicas que se concentraron y } \\
\text { redujeron su red en regiones no colindantes. }\end{array}$ \\
\hline GRUPO 8 & $\begin{array}{l}\text { Reducción alta } \\
(-25 \% \geq \mathrm{E}>-40 \%)\end{array}$ & $\begin{array}{l}4 \text { cooperativas de } \\
\text { crédito } \\
2 \text { cajas de ahorro } \\
4 \text { bancos } \\
\text { comerciales }\end{array}$ & $\begin{array}{c}\text { Dos sub-grupos: } \\
\text { - bancos con expansión a nivel nacional que redujeron su presencia en } \\
\text { todo el territorio pese a haber absorbido parte de la red de cajas, como } \\
\text { en el caso del Banco Sabadell. } \\
\text { - cajas caracterizadas por haber requerido ayudas públicas (Calvo y } \\
\text { Martín de Vidales 2014) }\end{array}$ \\
\hline GRUPO 9 & $\begin{array}{l}\text { Reducción muy } \\
\text { alta } \\
(-40 \% \geq E)\end{array}$ & $\begin{array}{l}1 \text { cooperativa de } \\
\text { crédito } \\
2 \text { cajas de ahorro } \\
2 \text { bancos } \\
\text { comerciales }\end{array}$ & $\begin{array}{l}\text { Dos tendencias: } \\
\text {-bancos medianos que vendieron o reestructuraron su red; } \\
\text { - cajas que requirieron intervención del FROB }\end{array}$ \\
\hline
\end{tabular}

Fuente: Elaboración propia con datos del Anuario Histórico Guía de la Banca de Ediban. 
En el caso de las cooperativas de crédito encontramos dos tendencias principales: En primer lugar, el denominado modelo tradicional o clásico (Palomo-Zurdo y Sanchís-Palacio, 2008), representado por las cajas rurales de menor tamaño, que se mantuvo estable o tendió a expandirse en el periodo estudiado, particularmente en territorios donde las cajas de ahorro experimentaron mayores dificultades y mayor contracción (Comunidad Valenciana, Madrid o Castilla-La Mancha). Esta expansión fue relativamente baja en términos absolutos, aunque en términos relativos llegó a duplicar la red de algunas cajas rurales muy pequeñas. Un caso atípico es Caja Rural de Castilla-La Mancha, que abrió en el periodo estudiado 26, 34 y 22 oficinas en las provincias de Albacete, Ciudad Real y Cuenca, respectivamente, donde previamente no tenía presencia, respondiendo a un proceso de expansión decidido y concentrado desde su territorio original en Toledo ${ }^{10}$, lo que supuso un aumento del $46,5 \%$ de su red. En segundo lugar, las cooperativas de mayor tamaño, algunas de las cuales habían seguido intensas estrategias expansivas anteriores a través de fusiones Grupo Cajas Rurales Unidas, con Cajamar y Ruralcaja- o en solitario -Caja Laboral- (Palomo-Zurdo y Sanchís-Palacio, 2008), sufrieron una contracción moderada de su red de sucursales, concentrándose en sus territorios de origen. En algunos casos, se redujo incluso la red autonómica para expandirse en un entorno más restringido (provincial) -Ipar Kutxa Rural-. En todo caso, esta tipología bancaria mostró la mayor capacidad de retención de su red de sucursales durante el periodo de crisis y un vínculo intenso con su territorio, en sintonía con la teoría de la prioridad de mercado (market preemption; Evanoff, 1988).

Figura. 3. Principales entidades en variación absoluta de sucursales (2008-2013), según provincia

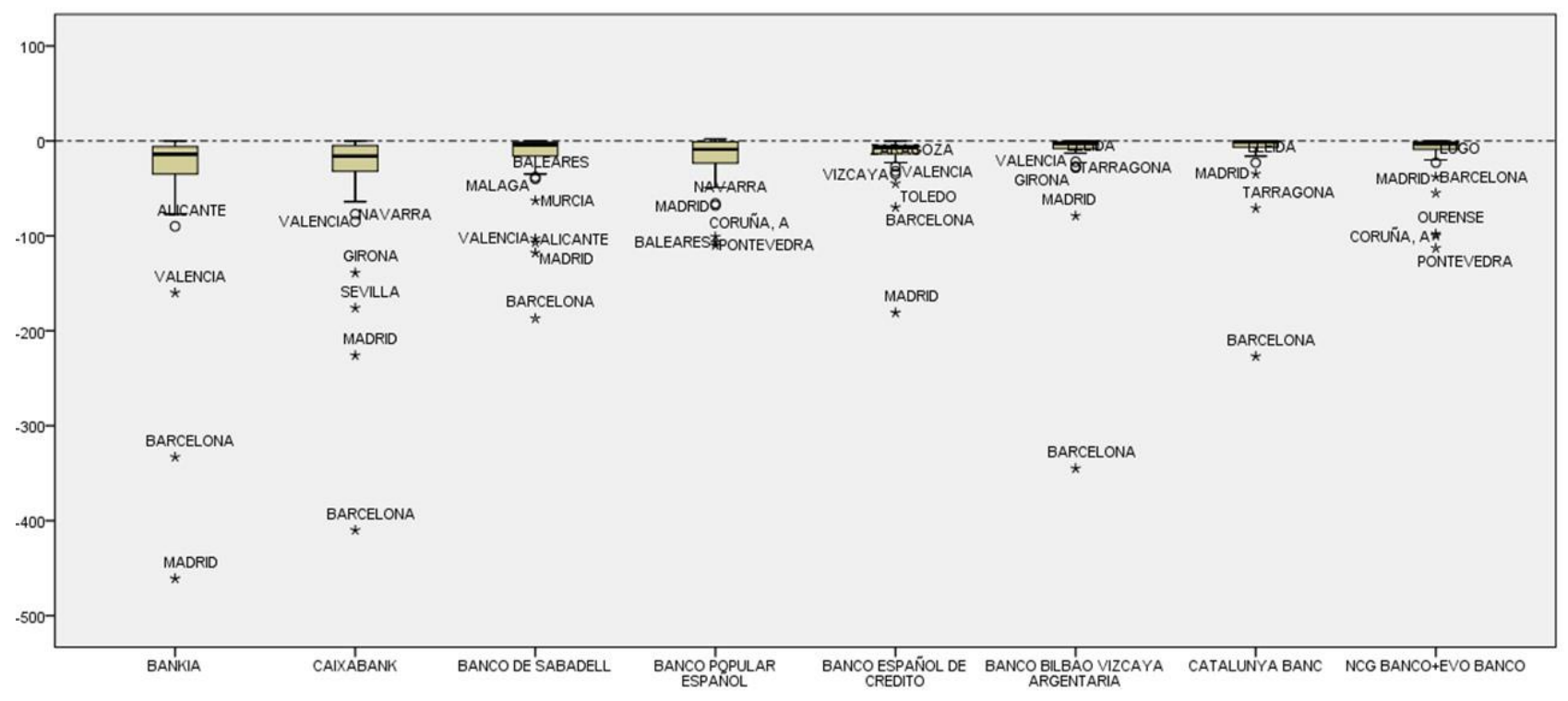

Fuente: Elaboración propia con datos del Anuario Histórico Guía de la Banca de Ediban.

En el caso de las cajas de ahorro vemos que el tamaño constituyó un factor moderador de la reducción de sucursales, pues las dos entidades más pequeñas -Caixa d'Estalvis de Ontinyent y Colonya-Caixa d'Estalvis de Pollença- fueron las que experimentaron menor impacto (nulo y ligera reducción) y actualmente siguen operando como cajas de ahorro. Un segundo grupo está formado por cajas que experimentaron dificultades en el marco de la crisis, incluso con necesidad de recurrir a las ayudas del FROB, pero que redujeron moderadamente su red. Encontramos entidades de tamaño mediano, con estrategias diversas e incluso opuestas, como las de Liberbank e Ibercaja Banco: la primera equilibró su red mediante una reducción mayor en sus provincias de origen y menor en territorios limítrofes; Ibercaja, sin embargo, se concentró en la comunidad aragonesa, eliminando sucursales externas. Debe recordarse que las entidades que requirieron ayudas públicas para solventar su déficit de capital y fueron calificadas como grupo 2 en base al MoU (BOE, 2012) se comprometieron a reducir su tamaño en una media del $30 \%$ y a reorientarse hacia el mercado minorista y el crédito a pymes (Calvo y Martín de Vidales, 2014). Finalmente encontramos que las entidades que requirieron ser nacionalizadas por el FROB, como Bankia, NGC Banco o Catalunya Banc

10 Esta entidad inició un plan de expansión justamente en 2010 que implicó incluso su denominación social en 2011 de Caja-Rural de Toledo a Caja Rural de Castilla-La Mancha. En la misma línea, GlobalCaja, la Caja Rural de Albacete, Ciudad Real y Cuenca, optó también por un proceso expansivo en Castilla-La Mancha, estableciendo en dicho periodo 6 oficinas en Toledo, provincia donde anteriormente no tenían representación. Esto parece responder conjuntamente a la identificación de un nicho de mercado por el desmantelamiento también intenso de oficinas del Banco de Castilla-La Mancha (anterior caja de ahorros) y a que las sucursales físicas siguen siendo la principal estrategia de entrada a un territorio. 
experimentaron una alta intensidad de reducción de su red. Un caso atípico entre las cajas fue Caixabank que, pese a no haber experimentado grandes dificultades ni presiones debidas a la recepción de ayudas, fue la segunda entidad en volumen absoluto de reducción de sucursales (figura 3), siguiendo una estrategia más parecida a la de grandes bancos comerciales como BBVA o Banco de Sabadell.

En cuanto a los bancos comerciales, encontramos una marcada dualidad de tendencias. Encontramos entidades que realizaron una apuesta expansiva: esto incluyó tanto a bancos pequeños que aumentaron su red regional -Banca Pueyo-, como a entidades muy grandes -Banco Santander- que crecieron a nivel nacional. Debe matizarse que Santander expandió sus sucursales mientras se disolvió la red de otra entidad del grupo: Banesto $^{11}$. Un caso particular fue la expansión de Deutsche Bank a través de las oficinas de Correos, en una experiencia de banca postal que se definió con voluntad de proximidad hacia el cliente. La otra tendencia está representada por bancos que apostaron claramente por la reducción de sucursales, la cual fue desde moderada a muy intensa, encontrando su extremo en entidades que han sufrieron una disolución o enajenación de gran parte de su red -Banesto, Barclays-.

Observamos un efecto-paradoja entre el análisis a nivel de subsector bancario y a nivel de entidades, particularmente en el caso de algunos bancos. En el análisis agregado observamos un mejor comportamiento sectorial de los bancos frente a las cajas, incluso observamos que aumentaron su red en diversos territorios. La reducción total del subsector durante la crisis se cifró en un $8,91 \%$, mientras que la red de cajas se redujo en un 33,93\%. Pero en el análisis por entidad vemos que la mitad de las entidades que generaron individualmente más de un $4 \%$ de variación de sucursales en el periodo fueron bancos (figura 3). Este efecto se debió a la absorción de cajas de ahorro por parte de los bancos comerciales y a las asimetrías existentes entre la decisión de cierre de las sucursales (el banco, una vez que la caja es parte del grupo) y la asignación del impacto (sobre la red perteneciente a las cajas de ahorro). Un ejemplo de este efecto paradoja es el Banco BBVA que durante este periodo absorbió tres cajas de ahorro catalanas (Caixa d'Estalvis Comarcal de Manlleu, Caixa d'Estalvis de Sabadell y Caixa d'Estalvis de Terrassa). En 2008 poseía 371 sucursales en la provincia de Barcelona, a las que incorporó 596 oficinas procedentes de dichas absorciones, cerrando a continuación 345 sucursales en la misma provincia. El saldo resultante fue una expansión provincial de la marca BBVA hasta las 622 sucursales en 2013, pero a efectos de impacto territorial supuso una pérdida de casi un 36\% de la red conjunta del grupo. Se puede afirmar que al menos un 16\% de la reducción de la red de las cajas se determinó una vez que pasó a ser parte de la banca comercial.

\section{Conclusiones}

Las dinámicas de reducción y concentración de sucursales bancarias durante el periodo 20082013 pueden clasificarse en dos grandes tendencias: Las provincias rurales parece que retuvieron un mayor nivel de calidad - menos saturación - en el servicio vía sucursal, gracias a un mayor mantenimiento de la red de cooperativas de crédito. Las zonas urbanas se enfrentaron a una reducción más intensa de la red de sucursales, junto con la absorción de buena parte de la infraestructura de las cajas de ahorro por la banca comercial. A la vez, las zonas urbanas experimentaron el crecimiento más intenso de la desigualdad socioeconómica. Puede afirmarse que este desigual comportamiento de las tipologías de entidades bancarias ha modificado los 'ecosistemas financieros' de las provincias españolas: con provincias rurales servidas por la banca social, y territorios urbanos preferidos por los bancos comerciales, que a la vez cierran sus antiguas sucursales y absorben parte de la red de las cajas de ahorro.

La contracción de la red bancaria resultó lógica y necesaria en el contexto estudiado, instada por las medidas aplicadas para garantizar la estabilidad del sector financiero español. No obstante, el retroceso del modelo de banca relacional puede haber generado repercusiones en cuanto a inclusión financiera: ejemplo de ello puede ser el crédito a los pequeños negocios, apoyado en muchas ocasiones en información relacional. Durante la crisis las restricciones de crédito por las dificultades de acceso de la banca a la financiación mayorista afectaron fuertemente a la economía real, a las pymes y a los hogares (Banco de España, 2012; Sudrià y Triay, 2014). En el ámbito de las economías domésticas, la necesidad de la banca relacional se incrementa ante fenómenos como el sobre-endeudamiento, el aumento de la morosidad y la necesidad de renegociaciones de deuda; con la demanda de asesoramiento personalizado frente a decisiones de ahorro e inversión en un entorno incierto y de productos complejos; o por la gestión de dificultades consecuencia de la adquisición de productos bancarios conflictivos como las participaciones preferentes o las hipotecas con cláusulas suelo. A falta de un indicador más preciso, se puede valorar el incremento de estas dificultades entre otras- respecto al uso de los servicios bancarios a través del número de reclamaciones registradas por el Banco de España: éstas se multiplicaron por siete entre 2005 y 2013, y es 2008 el año que inicia una clara tendencia de aumento (Banco de España, 2014:33).

11 De hecho, el efecto consolidado de las redes de Banco Santander y Banesto fue negativo, aunque moderado, y con mayor incidencia en provincias con grandes áreas metropolitanas como Madrid y Barcelona. 
Así, puede argumentarse que la variación de sucursales en el periodo más intenso de la crisis (2008-2013) no estuvo determinada tanto por factores sociodemográficos, como por el nivel de riesgo asumido por las entidades bancarias en particular, su solvencia y capacidad de reacción ante la crisis, y por la aplicación de criterios en su presencia territorial como la prioridad de mercado.

Una limitación del estudio es la asunción de una 'sucursal tipo', igualmente dotada en cuanto a infraestructura y personal, en todas las provincias y para todas las tipologías de entidad, lo cual no se ha podido contrastar por falta de acceso a este tipo de información a través de las bases de datos utilizadas. Debería profundizarse en el estudio de esta circunstancia, habitualmente no considerada en los estudios sobre exclusión financiera territorial. Otra limitación ha sido la falta de acceso a información interna de las entidades bancarias (por ejemplo, datos de rentabilidad y costes de la red de sucursales, umbrales, objetivos y políticas de cierre de oficinas, etc.). Esta limitación abre una futura línea de investigación relativa a la influencia de otros factores latentes en el proceso de reducción de sucursales.

En cuanto a futuras líneas de investigación, la mayor reducción de red experimentada por las zonas urbanas hace recomendable analizar la localización de las oficinas bancarias a un nivel micro-territorial, inferior incluso al nivel municipal. Esta intensa reducción, sumada al diferencial de desigualdad, puede haber supuesto una discriminación bancaria de determinados barrios y colectivos. El análisis cualitativo de las dificultades bancarias derivadas es otra línea de interés.

La crisis demostró que el mercado financiero es imperfecto, que las consecuencias sociales causadas por los intereses contrapuestos de diferentes grupos de interés pueden llegar a ser muy graves. La intervención del Estado Español para el rescate de entidades con graves problemas de solvencia demostró que no basta con considerar la intermediación bancaria como una mera cuestión de mercado, sino que implica responsabilidades para toda la sociedad. La Unión Europea ya ha garantizado el derecho a una cuenta bancaria para todos los ciudadanos (Directiva 2014/92/UE). En términos territoriales, una visión de los servicios bancarios como servicio básico implicaría garantizar su prestación con una cierta cobertura territorial y poblacional, como se realiza con los servicios farmacéuticos, de transporte o postales. Las dificultades de uso de los servicios bancarios - el concepto más relevante para la exclusión financiera en los países desarrollados- podrían agravarse aún más en ausencia de objetivos sociales en la prestación de los servicios bancarios. La presencia de objetivos sociales en las entidades bancarias no lastró necesariamente la cobertura bancaria durante la crisis: el ejemplo son las cooperativas de crédito, que mostraron una notable capacidad de resiliencia y que han sabido combinar la atención presencial con la transformación digital (Soler-Tormo y Melián-Navarro, 2012; Palomo-Zurdo et al. 2018).

La salida de la crisis debería haber servido para replantear de nuevo el modelo de banca social y su importancia en la recuperación de la dañada confianza de la ciudadanía. Quizá sea el momento para recuperar ideas, como el subsidio de costes entre clientes de mayor y menor rentabilidad, que garanticen el acceso a los servicios bancarios de toda la población. Revell (1989: 31) describió el doble objetivo de la banca social en sus inicios: socioeconómico, para evitar que las personas traspasaran la línea de la pobreza debido a sucesos imprevistos; y político, para evitar conflictos sobrevenidos a causa de la miseria 'manteniéndoles [a ciudadanos con escasos recursos] en las capas respetables de la sociedad'.

Si en terminología actual sustituimos 'respetabilidad' por 'integración', éste puede constituir el reto social más importante para la banca social española, en un entorno en el que la desigualdad tiende a acrecentarse.

\section{Referencias bibliográficas}

Aalbers, M. B. (2007) What types of neighbourhoods are redlined? Journal of Housing and the Built Environment, $\mathrm{N}^{\circ}$ 22, Vol. 2, pp. 177-198. https://doi.org/10.1007/s10901-007-9074-9.

Alamá, L., Conesa, D., Forte, A., y Tortosa-Ausina, E. (2015) The geography of Spanish bank branches. Journal of Applied Statistics, No 42, Vol. 4, pp. 722-744. https://doi.org/10.1080/02664763.2014.980792.

Alamá, L., y Tortosa-Ausina, E. (2012) Bank branch geographic location patterns in Spain: Some implications for financial exclusion. Growth and Change, $\mathrm{N}^{\circ}$ 43, Vol. 3, pp. 505-543. https://doi.org/10.1111/j.14682257.2012.00596.x.

Anderloni, L., Bayot, B., Bledowski, P., Iwanicz-Drozdowska, M., y Kempson, E. (2008) Financial services provision and prevention of financial exclusion. Bruselas, Comisión Europea.

Anderloni, L., y Carluccio, E. M. (2007) Access to bank accounts and payment services. En Anderloni et al (2007) New frontiers in banking services, pp. 5-105. Springer.

Banco de España (2012) Encuesta del BCE sobre el acceso de las pymes a la financiación. Boletín Económico, abril 2012, pp. 73-80.

Banco de España (2014) Memoria de Reclamaciones 2013.

Banco Mundial (2014) Global financial development report 2014: Financial inclusion. Washington, DC: World Bank. DOI:10.1596/978-0-8213-9985-9.

Banco Mundial (2019) Global Findex Database. http://www.worldbank.org/en/programs/globalfindex [Visitado 14/07/19]. 
Bernad C., Fuentelsaz L., y Gómez J. (2008) Deregulation and its long-run effects on the availability of banking services in low-income communities. Environment and Planning A, No 40, Vol. 7, 1681.

Bowman A., Erturk I., Froud J., Johal S., Law J., Leaver A. y Williams K. (2014) The end of the experiment. Manchester University Press.

BOE (2012) Memorando de Entendimiento sobre condiciones de Política Sectorial Financiera, hecho en Bruselas y Madrid el 23 de julio de 2012, y Acuerdo Marco de Asistencia Financiera, hecho en Madrid y Luxemburgo el 24 de julio de 2012. Boletín Oficial del Estado, 10 de diciembre de 2012.

Carbó, S., Gardener E.P., y Molyneux P. (2005) Financial exclusion. Palgrave MacMillan, Basingstoke.

Carbó, S., y López del Paso, R. (2002) La inclusión financiera: Un paso cualitativo más, Cuadernos de Información Económica, $\mathrm{N}^{\mathrm{o}} 170$, pp. 79-90.

Carbó, S., y Rodríguez, F. (2015) Concepto y evolución de la exclusión financiera: Una revisión. Cuadernos de Información Económica, $\mathrm{N}^{\mathrm{o}} 244$, pp. 73-83.

Cruz-García, P., Fernández de Guevara, J., y Maudos, J. (2018) Banking concentration and competition in Spain: the impact of the crisis and restructuring. Financial Stability Review (Revista de Estabilidad Financiera), № 34 . Banco de España.

Davies, S., Finney, A., y Hartfree, Y. (2016) The poverty premium-when low-income households pay more for essential goods and services. University of Bristol. DOI: 10.13140/RG.2.2.11648.33280.

Degryse, H., Matthews, K., y Zhao, T. (2018) SMEs and Access to Bank Credit: Evidence on the Regional Propagation of the Financial Crisis in the UK. Journal of Financial Stability, No 38, pp. 53-70. DOI:10.1016/j.jfs.2018.08.006.

Delgado, J., Salas, V., y Saurina, J. (2007) Joint size and ownership specialization in bank lending. Journal of Banking \& Finance, $\mathrm{N}^{\mathrm{o}} 31$, Vol. 12, pp. 3563-3583.

Delgado, J., Saurina, J., y Townsend, R. (2008) Estrategias de expansión de las entidades de depósito españolas. Una primera aproximación descriptiva. Revista de Estabilidad Financiera, No 15, pp. 101-117.

Demirguc-Kunt, A., Klapper, L., Singer, D., Ansar, S., y Hess, J. (2018) The Global Findex Database 2017: Measuring financial inclusion and the fintech revolution. The World Bank. https://doi.org/10.1596/978-1-4648-1259-0.

Dymski, G. A., y Veitch, J. M. (1996) Financial transformation and the metropolis: Booms, busts, and banking in Los Angeles. Environment and Planning A, No 28, Vol. 7, pp. 1233-1260.

EBF (2013) European Banking Sector. Facts \& Figures 2013. Bruselas: European Banking Federation.

Evanoff, D. (1988) Branch banking and service accessibility. Journal of Money, Credit and Banking, № 20, Vol. 2, pp. 191-202.

Fernández-Olit, B. (2012) Financial inclusion in Spain: a comparative study among Banks, Savings Banks and Cooperative Banks, Perspectives, N ${ }^{\circ}$ 65. European Savings Banks Group. Disponible en https://www.wsbiesbg.org/SiteCollectionDocuments/Perspectives\%2065.pdf.

Fernández-Olit, B., Paredes-Gázquez, J.D. y de la Cuesta-González, M. (2018) Are Social and Financial Exclusion Two Sides of the Same Coin? An Analysis of the Financial Integration of Vulnerable People. Social Indicators Research, $\mathrm{N}^{\circ}$ 135, Vol. 1, pp. 245-268, https://doi.org/10.1007/s11205-016-1479-y.

French S., Leyshon A. y Meek S. (2013) The changing geography of British bank and building society branch networks, 2003-2012. University of Nottingham Working Paper.

García-Montalvo, J. (2014) Crisis financiera, reacción regulatoria y el futuro de la banca en España. Estudios de Economía Aplicada, № 32, Vol. 2, pp. 2-32.

Gärtner, S. y Fernández, J. (2018) The banking systems of Germany, the UK and Spain form a spatial perspective: The Spanish case, IAT Discussion Paper, No. 18/02, Institut Arbeit und Technik (IAT), Gelsenkirchen. Disponible en http://hdl.handle.net/10419/177839.

Goddard, J., Molyneux, P., y Wilson, J. O. (2009) The financial crisis in Europe: evolution, policy responses and lessons for the future. Journal of financial regulation and compliance, $\mathrm{N}^{\mathrm{o}}$ 17, Vol. 4, pp. 362-380. DOI: $10.1108 / 13581980911004352$.

Hair, J. F., Black, W. C., Babin, B. J., Anderson, R. E., y Tatham, R. L. (2006) Multivariate data analysis. Pearson Prentice Hall, Upper Saddle River, NJ.

Harris, M., Cox, K., Musgrove, C. y Ernstberger, K. (2016) Consumer preferences for banking technologies by age groups, International Journal of Bank Marketing, $\mathrm{N}^{\circ}$ 34, Vol. 4, pp. 587-602. https://doi.org/10.1108/IJBM-042015-0056.

Helsper, E. J., y Reisdorf, B. C. (2017) The emergence of a "digital underclass" in Great Britain and Sweden: Changing reasons for digital exclusion. New media \& society, $\mathrm{N}^{\mathrm{o}}$ 19, Vol. $_{\text {, }}$, pp. $1253-1270$. https://doi.org/10.1177/1461444816634676.

Horska, E., Szafrańska, M., y Matysik-Pejas, R. (2013) Knowledge and financial skills as the factors determining the financial exclusion process of rural dwellers in Poland. Agricultural Economics, No 59, Vol. 1, pp. 29-37.

Joassart-Marcelli, P., y Stephens, P. (2010) Immigrant banking and financial exclusion in Greater Boston. Journal of Economic Geography, No 10, Vol. 6, pp. 883-912. https://doi.org/10.1093/jeg/lbp052.

Kashian, R. D., Tao, R., y Perez-Valdez, C. (2015) Banking the unbanked: Bank deserts in the United States. University of Wisconsin, Working Paper.

Leyshon, A., Burton, D., Knights, D., Alferoff, C., Signoretta, P. (2004) Towards an ecology of retail financial services: Understanding the persistence of door-to-door credit and insurance providers. Environment and Planning A, $\mathrm{N}^{\mathrm{o}} 36$, Vol. 4, pp. 625-646. https://doi.org/10.1068/a3677.

Leyshon, A., Signoretta, P., French, S. (2006) The changing geography of British bank and building society branch networks, 1995-2003. University of Nottingham, School of Geography, Working Paper. 
Martin-Oliver, A. (2019) Financial exclusion and branch closures in Spain after the Great Recession, Regional Studies, $\mathrm{N}^{\circ}$ 53, Vol. 4, pp. 562-573, DOI: 10.1080/00343404.2018.1462485.

Maudos, J. (2017) Bank restructuring and access to financial services: the Spanish case. Growth and Change, $\mathrm{N}^{\circ} 48$, Vol. 4, pp. 963-990. https://doi.org/10.1111/grow.12211.

Menéndez, A., Gorris, A., \& Dejuán, D. (2017) La evolución económica y financiera de las empresas no financieras españolas durante la crisis económica y primeros años de la recuperación. Un análisis comparado con la UEM. Boletín económico, $\mathrm{N}^{\mathrm{o}} 2$. Banco de España.

Palomo-Zurdo, R. J., y Sanchís-Palacio, J. R. (2008) Un análisis del crédito cooperativo en España: Situación actual, expansión territorial y proyección estratégica. Estudios de Economía Aplicada, No 26, Vol. 1, pp. 27-41.

Palomo-Zurdo, R.J., Fernández-Torres, Y. y Gutiérrez-Fernández, M. (2018) Banca cooperativa y transformación digital: hacia un nuevo modelo de relación con sus socios y clientes. REVESCO. Revista de Estudios Cooperativos, No 129, pp. 161-182. DOI: 10.5209/REVE.62490.

Papi, L., Sarno, E., y Zazzaro, A. (2017) The geographical network of bank organizations: issues and evidence for Italy. En Martin, R. y Pollard, J. (eds.), Handbook on the Geographies of Money and Finance, pp. 156-197.

Quintás Seoane, J. R. (2006) Las cajas de ahorros en el ámbito de la responsabilidad social corporativa. Papeles de Economía Española, No 108, pp. 128-141.

Revell, J. (1989) El futuro de las cajas de ahorros. Estudio de España y del resto de Europa. Madrid: Fundación FIES de la CECA.

Richez-Battesti N. y Leseul G. (2016) Cooperative Banks in France: Emergence, Mutations and Issues. En: Karafolas S. (eds) Credit Cooperative Institutions in European Countries. Contributions to Economics. Springer, Cham

Soler-Tormo, F., y Melián-Navarro, A. (2012) Cooperativas de crédito y banca social: viejas y nuevas respuestas éticas y solidarias a problemas de siempre. REVESCO. Revista de Estudios Cooperativos, Tercer Cuatrimestre, № 109 , pp. 45-80. DOI: https://doi.org/10.5209/rev_REVE.2012.v109.40655.

Sudrià i Triay, C. (2014) Las crisis bancarias en España: Una perspectiva histórica. Estudios de Economía Aplicada, N ${ }^{\circ}$ 32, Vol. 2, pp. 1-24.

Waite, N., y Devlin, J. (2012) Fairness in financial services: Sector analysis. Nottingham: Nottingham University Business School.

Zurita, J. (2014) La reforma del sector bancario español hasta la recuperación de los flujos de crédito. BBVA Research, Documento de trabajo, No 12, 2014.

\section{Apéndice: Pertenencia a conglomerados según comportamiento de tipologías bancarias}

\begin{tabular}{|l|l|r|r|}
\hline $\mathbf{N}^{\mathbf{0}}$ caso & \multicolumn{1}{|c|}{ Provincia } & Congl. & Distancia \\
\hline 1 & ÁLAVA & 2 & .127 \\
\hline 2 & ALBACETE & 2 & .366 \\
\hline 3 & ALICANTE & 1 & .241 \\
\hline 4 & ALMERÍA & 2 & .124 \\
\hline 5 & ASTURIAS & 2 & .106 \\
\hline 6 & ÁVILA & 2 & .207 \\
\hline 7 & BADAJOZ & 2 & .164 \\
\hline 8 & BALEARES & 1 & .221 \\
\hline 9 & BARCELONA & 1 & .358 \\
\hline 10 & BURGOS & 2 & .201 \\
\hline 11 & CÁCERES & 2 & .169 \\
\hline 12 & CÁDIZ & 1 & .198 \\
\hline 13 & CANTABRIA & 2 & .222 \\
\hline 14 & CASTELLON & 1 & .196 \\
\hline 15 & CEUTA & 1 & .211 \\
\hline 16 & CIUDAD REAL & 2 & .262 \\
\hline 17 & CÓRDOBA & 2 & .146 \\
\hline 18 & CORUÑA, A & 2 & .593 \\
\hline 19 & CUENCA & 2 & .339 \\
\hline 20 & GIRONA & 1 & .319 \\
\hline 21 & GRANADA & 2 & .096 \\
\hline & & & \\
\hline
\end{tabular}

\begin{tabular}{|l|l|r|r|}
\hline $\mathbf{N}^{\mathbf{0}}$ caso & \multicolumn{1}{|c|}{ Provincia } & Congl. & Distancia \\
\hline 27 & LEÓN & 2 & .095 \\
\hline 28 & LLEIDA & 1 & .229 \\
\hline 29 & LUGO & 2 & .114 \\
\hline 30 & MADRID & 2 & .154 \\
\hline 31 & MÁLAGA & 1 & .194 \\
\hline 32 & MELILLA & 1 & .312 \\
\hline 33 & MURCIA & 1 & .184 \\
\hline 34 & NAVARRA & 2 & .153 \\
\hline 35 & OURENSE & 2 & .323 \\
\hline 36 & PALENCIA & 1 & .207 \\
\hline 37 & PALMAS, LAS & 2 & .147 \\
\hline 38 & PONTEVEDRA & 2 & .286 \\
\hline 39 & RIOJA, LA & 2 & .173 \\
\hline 40 & SALAMANCA & 2 & .197 \\
\hline 41 & SEGOVIA & 2 & .157 \\
\hline 42 & SEVILLA & 2 & .197 \\
\hline 43 & SORIA & 1 & .237 \\
\hline 44 & TARRAGONA & 1 & .468 \\
\hline 45 & TENERIFE & 2 & .072 \\
\hline 46 & TERUEL & 2 & .200 \\
\hline 47 & TOLEDO & 2 & .086 \\
\hline & & & \\
\hline
\end{tabular}




\begin{tabular}{|l|l|r|r|}
\hline 22 & GUADALAJARA & 2 & .118 \\
\hline 23 & GUIPUZCOA & 2 & .111 \\
\hline 24 & HUELVA & 2 & .133 \\
\hline 25 & HUESCA & 1 & .155 \\
\hline 26 & JAÉN & 2 & .129 \\
\hline
\end{tabular}

\begin{tabular}{|l|l|r|r|}
\hline 48 & VALENCIA & 1 & .179 \\
\hline 49 & VALLADOLID & 1 & .183 \\
\hline 50 & VIZCAYA & 2 & .081 \\
\hline 51 & ZAMORA & 2 & .119 \\
\hline 52 & ZARAGOZA & 1 & .160 \\
\hline
\end{tabular}

